\title{
Total antioxidant capacity of refrigerated orange juice treated with pulsed electric fields
}

\author{
C. Cortés, F. Barba, M. J. Esteve, R. González and A. Frígola \\ Nutrition and Food Chemistry, Faculty of Pharmacy, University of Valencia, Avd. Vicent Andres Estelles s/n, Burjassot, \\ Valencia, Spain
}

Orange juice is an important source of carotenoids and ascorbic acid, a nutrient that besides its vitamin action is valuable for its antioxidant effect, stimulation of the immune system and other health benefits that are being actively investigated and reported, such as inhibition of the formation of cancer-causing N-nitroso compounds in the stomach $^{(1)}$. During processing and/or storage orange juice undergoes an important number of undesirable effects on some nutrients, antioxidant compounds, colour, flavour and texture. The use of pulsed electric fields (PEF) is an emerging technology in the field of food preservation ${ }^{(2)}$. The aim of the present work was to study the antioxidant capacity of the orange juice treated with PEF $(30 \mathrm{kV} / \mathrm{cm}, 100 \mu \mathrm{s})$ in comparison with orange juice subjected to conventional thermal treatments $\left(90^{\circ} \mathrm{C}\right.$ during $\left.20 \mathrm{~s}\right)$, as well as changes in orange juice stored at 2 and $10^{\circ} \mathrm{C}$, using a method adapted from that of Miller et al. ${ }^{(3)}$. The Trolox equivalent antioxidant capacity (TEAC) of the samples was (mmol Trolox/l) 4.03 (SD 0.04), 3.51 (SD 0.04) and 2.49 (SD 0.20) for untreated, PEF-treated and pasteurized orange juice respectively. Thus, TEAC decreased significantly $(P<0.05)$ after the orange juice was processed by both types of treatment; the decrease being greater in the pasteurized juice (38.2\%) than in the PEF-treated juice $(12.9 \%)$. Thus, PEF treatment of orange juice had an antioxidant capacity more similar to that of the untreated juice. The total antioxidant capacities of samples during refrigerated storage are shown in the Table. The results show a decrease with time at both temperatures, although the decrease was higher in the samples stored at $10^{\circ} \mathrm{C}$. Compared with conventional pasteurization, PEF treatment led to a higher total antioxidant activity of orange juice immediately after processing, as well as during storage at $2-10^{\circ} \mathrm{C}$.

\begin{tabular}{lcccccccc}
\hline \multicolumn{7}{c}{ TEAC $(\mathrm{mmol}$ Trolox/l) } \\
\hline Temperature $\left({ }^{\circ} \mathrm{C}\right)$ & Period of storage (weeks) & 0 & 1 & 2 & 3 & 4 & 6 & 7 \\
\hline 2 & PEF juice & 3.51 & 3.22 & 2.98 & 2.94 & 2.33 & 2.23 & 2.21 \\
& Pasteurized juice & 2.49 & 1.93 & 2.10 & 2.40 & 1.83 & 1.80 & 1.80 \\
10 & PEF juice & 3.51 & 2.375 & 2.10 & 2.37 & 1.54 & 1.53 & - \\
& Pasteurized juice & 2.49 & 2.02 & 2.15 & 2.52 & 1.74 & 1.70 & - \\
\hline
\end{tabular}

This study was carried out with funds from the Spanish Ministry of Science and Technology and European Regional Development Funds (ERDF) (Project AGL-2003-05236-C02-02 and AGL-2006-13320-C03-03).

1. Valkoa M, Rhodesb CJ, Moncola J, Izakovica M \& Mazur M (2006) Chem Biol Interact 160, 1-40.

2. Min S, Jin ZT, Yeom H, Min SK \& Zhang QH (2003) J Food Sci 68, 1265-1271.

3. Miller NJ, Diplock AT, Rice-Evans C, Davies MJ, Gopinathan V \& Milne A (1993) Cli Sci 84, 407-412. 